\title{
Representing El Niño in coupled ocean- atmosphere GCMs: the dominant role of the atmospheric component
}

Article

Published Version

Guilyardi, E. and Slingo, J. (2004) Representing El Niño in coupled ocean-atmosphere GCMs: the dominant role of the atmospheric component. Journal of Climate, 17 (24). pp. 46234629. ISSN 1520-0442 doi: https://doi.org/10.1175/JCLI3260.1 Available at https://centaur.reading.ac.uk/5882/

It is advisable to refer to the publisher's version if you intend to cite from the work. See Guidance on citing.

To link to this article DOI: http://dx.doi.org/10.1175/JCLI-3260.1

Publisher: American Meteorological Society

All outputs in CentAUR are protected by Intellectual Property Rights law, including copyright law. Copyright and IPR is retained by the creators or other copyright holders. Terms and conditions for use of this material are defined in the End User Agreement.

$\underline{\text { www.reading.ac.uk/centaur }}$ 
Central Archive at the University of Reading

Reading's research outputs online 


\title{
LETTERS
}

\section{Representing EI Niño in Coupled Ocean-Atmosphere GCMs: The Dominant Role of the Atmospheric Component}

\author{
E. Guilyardi,*+ S. Gualdi, ${ }^{*}$ J. Slingo,* A. Navarra, ${ }^{*}$ P. Delecluse, ${ }^{+}$J. Cole, ${ }^{*}$ G. Madec, $@$ \\ M. Roberts, \& M. LATIF, $* *$ AND L. TERRAY ${ }^{+}+$ \\ *CGAM, Department of Meteorology, University of Reading, Reading, United Kingdom \\ ${ }^{+}$Laboratoire des Sciences du Climat et de L'Environnement, IPSL, Gif-sur-Yvette, France \\ \#Istituto Nazionale di Geofisica e Vulcanologia, Bologna, Italy

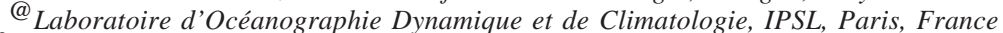 \\ ${ }^{\&}$ Hadley Centre for Climate Prediction and Research, Exeter, Devon, United Kingdom \\ **Institut fuer Meereskunde, Kiel, Germany \\ ++ CERFACS, Toulouse, France \\ 7 October 2003 and 16 April 2004
}

\begin{abstract}
A systematic modular approach to investigate the respective roles of the ocean and atmosphere in setting El Niño characteristics in coupled general circulation models is presented. Several state-of-the-art coupled models sharing either the same atmosphere or the same ocean are compared. Major results include 1) the dominant role of the atmosphere model in setting El Niño characteristics (periodicity and base amplitude) and errors (regularity) and 2) the considerable improvement of simulated El Niño power spectra-toward lower frequency-when the atmosphere resolution is significantly increased. Likely reasons for such behavior are briefly discussed. It is argued that this new modular strategy represents a generic approach to identifying the source of both coupled mechanisms and model error and will provide a methodology for guiding model improvement.
\end{abstract}

\section{Introduction}

Errors in the simulation of El Niño have been cited in the Intergovernmental Panel on Climate Change (IPCC) Third Assessment Report (Houghton et al. 2001) as a major source of uncertainty in projections of future climate change. Indeed, current state-of-the-art coupled models display a wide diversity of behavior and concomitant skill. In an attempt to understand the source of errors in these models, a number of intercomparison studies, which have documented the mean climate and variability of the tropical Pacific region, have been initiated (Neelin et al. 1992; Mechoso et al. 1995; Delecluse et al. 1998; Latif et al. 2001; Davey et al. 2001; AchutaRao and Sperber 2002). These studies highlighted the diverse behavior of coupled GCMs, with a wide range of amplitudes, periodicities, and seasonalities in the simulations of El Niño. They concluded, explicitly or implicitly, that "model diversity makes it difficult to clearly identify the origin of model deficiencies." Sev-

Corresponding author address: Dr. E. Guilyardi, Laboratoire des Sciences du Climat et de l'Environnement, IPSL, Bat. 701, Orme des Merisiers, 91191 Gif-sur-Yvette, France.

E-mail: ericg@met.rdg.ac.uk eral strategies have been proposed to overcome the limitation of these previous comparisons. Some studies have explored the reasons for the ENSO behavior in particular models by changing a fixed set of parameterizations and/or resolution in one of the components (Raynaud et al. 2000; Meehl et al. 2001) as previously done with simpler ENSO models (Schopf and Suarez 1990; Kirtman 1997; Fedorov and Philander 2000). This approach has clear benefits for understanding the behavior of a particular model but, because of the diversity of coupled model behavior, does not guarantee that the feedbacks dominant in one particular model may apply to others or that common biases among models can be attributed to common factors. Schneider (2002) went one step further in comparing the tropical mean state of two coupled models by swapping either the numerics and/or the parameterization of the two atmosphere models. The exploration of multimodel ensemble El Niño forecasts also led to the coupling of several atmosphere models together with ocean models (Schneider et al. 2003). These recent studies attributed most of the model errors in the mean state or in the El Niño forecast to the atmospheric component.

In this study, we aim to investigate the respective 


\section{Modular coupling approach}

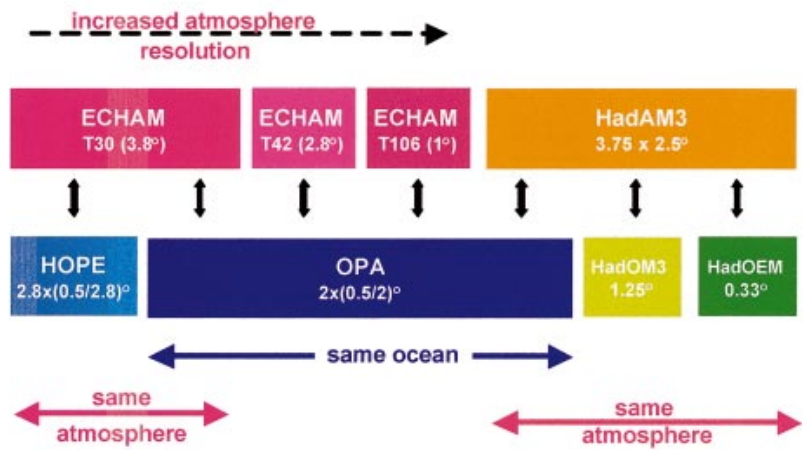

FIG. 1. The modular coupling approach and associated ocean and atmosphere GCMs used in this study. The horizontal resolution of the configurations used are specified.

roles of the ocean and atmosphere in setting the amplitude and frequency of El Niño in a number of coupled models. A systematic modular approach is used where one component model (ocean or atmosphere) is coupled to a number of models of the other component (atmosphere or ocean) and integrated for more than $100 \mathrm{yr}$. We argue that this represents a generic approach to identify the source of model error and will provide a mechanism for guiding model improvement. The focus of this letter is on the behavior of El Niño, its amplitude, regularity, and periodicity. A detailed analysis of the possible mechanisms that may give rise to the El Niño characteristics described here will be the subject of a later, more extensive study but are discussed in general terms at the end of the letter.

\section{Methodology}

Several recent collaborative projects in Europe-most notably the European Union (EU) Framework Programme V (FP5) Scale Interactions Experiments (SINTEX; see special issue of Ann. Geophys., 2003, Vol. 46, No. X) and the Hadley Centre/Centre for Global Atmospheric Modelling (CGAM) project to create the
HadOPA model (more info available online at http:// www.met.rdg.ac.uk./ ericg/hadopa_project.html) ${ }^{1}$ have made it possible for the first time to exchange components of a coupled model with relative ease and via the Ocean Atmosphere Sea Ice Soil (OASIS) coupler developed at the Centre Européen de Recherche et de Formation Avancée en Calcul Scientifique (CERFACS; Valcke et al. 2000).

Here we describe the results from seven global coupled simulations of at least $100 \mathrm{yr}$ long, using various combinations of four different atmospheric GCMs and four different ocean GCMs (Fig. 1; Table 1). We can identify different (sometimes overlapping) families: 1) the ECHAM family, with the Hamburg atmospheric model ECHAM4 at several resolutions and coupled to two different ocean models; 2) the HadAM3 family, sharing the atmosphere component of the Met Office Unified Model, but again differing oceans; and 3) the OPA family, sharing the LODYC global ocean model. In all cases, no flux correction is used and the resolution of the components (shown in Fig. 1) is standard, except for the high-resolution ECHAM4-T106/OPA simulation. It is important to note that the common component of each family has not been independently "tuned" for each of the coupled models; in each case, the atmosphere (ocean) module is exactly the same, and, in some cases, even the same binary executable.

Several of these coupled models have been studied individually by other authors who have documented their ENSO behavior in some detail. As in the previous intercomparison of coupled models (Latif et al. 2001; Davey et al. 2001; AchutaRao and Sperber 2002), the various model combinations given in Table 1 simulate the mean state and the seasonal cycle of the tropical Pacific with some fidelity (Fig. 2). Most have the correct seasonal phase locking of El Niño, that is, the El Niño SST anomalies peak in boreal winter (Fig. 2b). In these respects they can be considered state-of-the-art coupled

${ }^{1}$ The HadOPA model consists of the third Hadley Centre AGCM (HadAM3) coupled to the Laboratoire d'Océanographie Dynamique et de Climatologie (LODYC). OGCM (OPA).

TABLE 1. Description of the simulations and associated modularity (shared components). The actual length of simulations may be longer; the length refers to the subset used here. The ECHAM4-T106/OPA-mod is a rerun of the ECHAM-T106/OPA simulation with a modified coupling (see text). ENSO frequencies are the dominant power(s) as defined by peaks above 0.7 in the normalized spectra shown in Fig. 3. The ENSO amplitude is computed as the standard deviation of the Niño-3 region $\left(5^{\circ} \mathrm{S}-5^{\circ} \mathrm{N}, 150^{\circ}-90^{\circ} \mathrm{W}\right) \mathrm{SST}$ anomalies.

\begin{tabular}{llccc}
\hline \hline \multicolumn{1}{c}{ Model atmosphere-ocean } & Shared component(s) & Length $(\mathrm{yr})$ & El Niño frequencies $(\mathrm{yr})$ & $\begin{array}{c}\text { El Niño amplitude } \\
\left({ }^{\circ} \mathrm{C}\right)\end{array}$ \\
\hline ECHAM4-T30/OPA & ECHAM4-T30+OPA & 200 & 2.2 & 0.63 \\
ECHAM4-T42/OPA & OPA & 200 & $2.2-2.8$ & 0.54 \\
ECHAM4-T106/OPA & ECHAM4-T106+OPA & 100 & $2.6-3.6-5.7$ & 0.74 \\
ECHAM4-T106/OPA-mod & ECHAM4-T106+OPA & 100 & $2.7-4.3$ & 0.67 \\
ECHAM4-T30/HOPE-G & ECHAM4-T30 & 200 & 2.0 & 1.22 \\
HadAM3/OPA & HadAM3+OPA & 100 & 3.5 & 1.79 \\
HadAM3/HadOM3 & HadAM3 & 200 & 3.4 & 1.01 \\
HadAM3/HadEOM & HadAM3 & 140 & $2.4-3.2$ & 1.18 \\
Observations (HadISST1.1) & & 100 & $3.5-5.2$ & 0.80 \\
\hline
\end{tabular}


a) Seasonal cycle amplitude

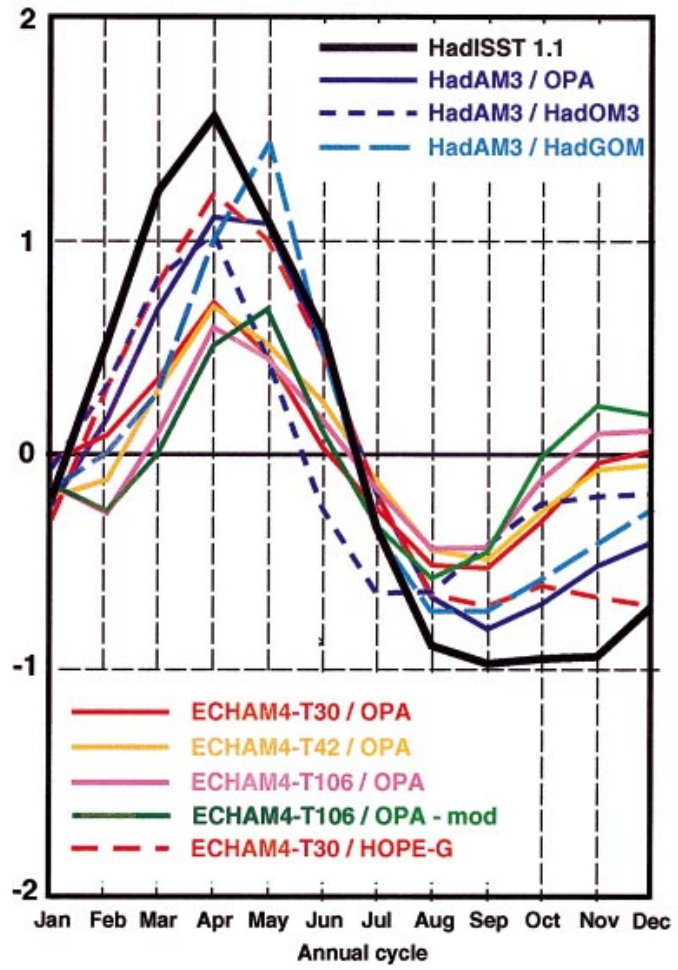

b) Standard deviation seasonal cycle

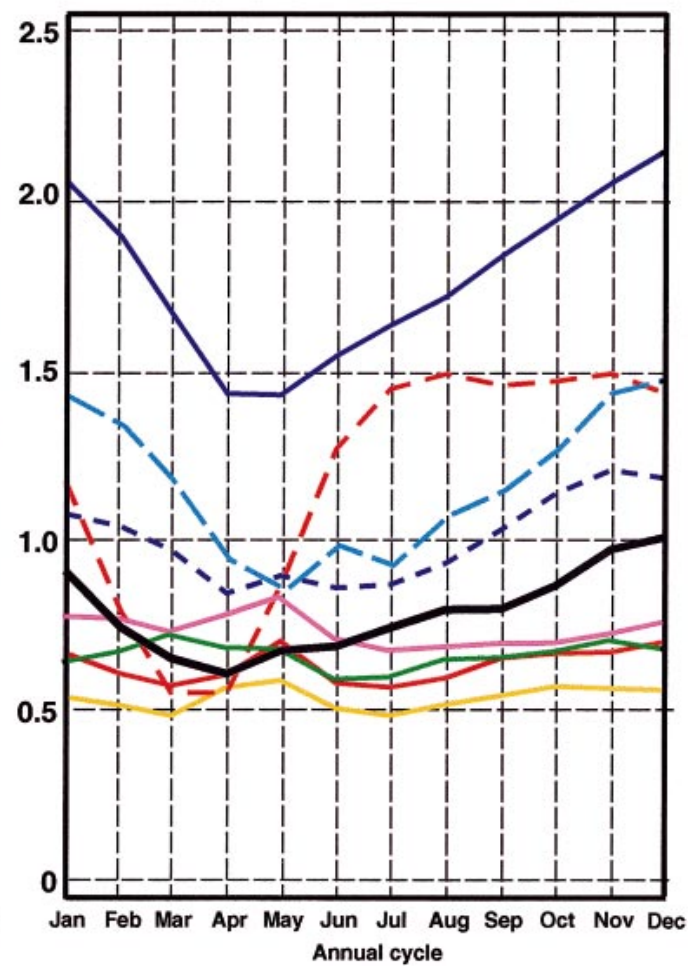

FIG. 2. SST seasonal cycle in the Niño-3 region for the models in Table 1: (a) amplitude (annual mean removed) and (b) monthly std dev.

models. Nevertheless, model atmosphere families exhibit marked differences. For instance, the ECHAM4/ OPA family has a smaller (but closer to observed) standard deviation than the HadAM3 family together with a weaker seasonal phase lock (Table 1 and Fig. 2b).

\section{Results}

In this paper, we focus exclusively on the behavior of El Niño as described by the SST variability in the equatorial eastern Pacific. The normalized power spectra of the monthly SST anomalies in the Niño-3 region, $\left(5^{\circ} \mathrm{S}-5^{\circ} \mathrm{N}, 150^{\circ}-90^{\circ} \mathrm{W}\right)$ are shown in Fig. 3. The spectra are computed using a Tukey filtering with a 20 -yr window. Based on the individual analysis of significant peaks for each nonnormalized time series, a common normalized significance threshold of 0.7 is defined (Fig. 3 ). The reference observations are obtained from 100 yr (1900-99) of the Hadley Centre Sea Ice and Sea Surface Temperature (HadISST1.1) dataset (Rayner et al. 2003). These spectra show the dominant time scales of low-frequency, interannual variability in the various model combinations and in the real world. The observed spectrum shows that El Niño has two dominant time scales, one near $5 \mathrm{yr}$ and the other close to $3.5 \mathrm{yr}$.

The spectra from the various coupled models display some interesting characteristics. First, and with the no- table exception of the high atmosphere resolution ECHAM4-T106/OPA coupled model, none of the coupled models capture the low-frequency mode of the observed phenomenon. Instead, all show a marked concentration of power at a single, preferred-too highfrequency. This apparent regularity is a well-known feature of coarse coupled GCMs and is confirmed by a sample of Niño-3 SST anomaly time series (Figs. 4a,b) compared to observations (Fig. 4d). However, the most striking result in Fig. 3a is the clear separation in El Niño periodicity between the HadAM3 and ECHAM4 families, with the former preferring a 3-yr and the latter a 2-yr El Niño cycle, regardless of which ocean component is used. This result, demonstrating that the atmosphere model apparently has a dominant influence on the periodicity of El Niño in coupled GCMs, will be discussed later.

The role of the atmosphere model in controlling the periodicity of El Niño, suggested by Fig. 3a, is further reinforced by the results shown in Fig. $3 \mathrm{~b}$ where the impact of atmospheric model resolution is highlighted. Effectively, the varying resolution versions of ECHAM4 are behaving as different atmospheric models because they handle the nonlinear interactions in space and time differently. The various resolutions of the ECHAM4 atmosphere model demonstrate a remarkable influence on the El Niño periodicity. As the resolution 


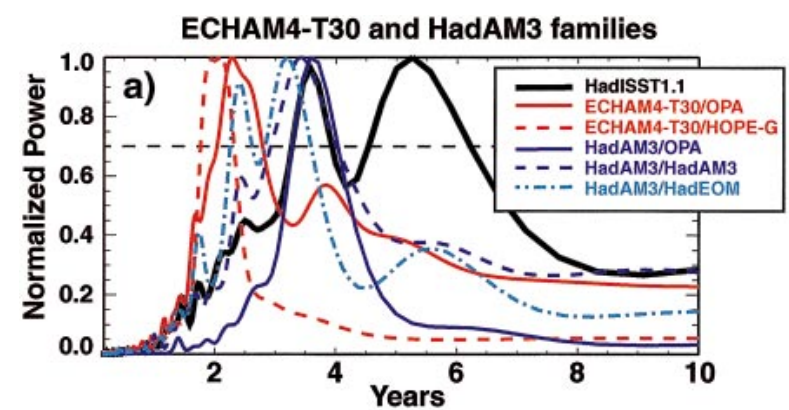

Impact of atmosphere resolution

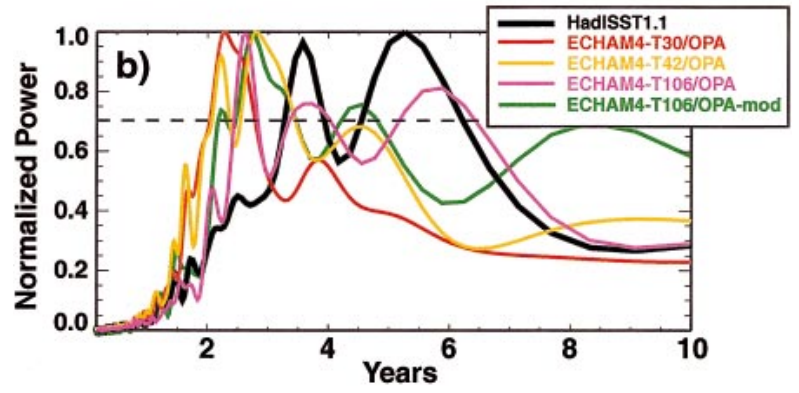

FIG. 3. Normalized spectra of Niño-3 SST monthly anomalies: (a) ECHAM4-T30 and HadAM3 families and (b) the impact of atmosphere resolution. Observations from HadISST1.1 dataset (thick black line). The dominant peaks are defined as those exceeding 0.7.

increases, the simulated El Niño becomes less regular (Fig. 4c; cf. Fig. 4a), and the power at lower frequencies is significantly increased (Fig. 3b). For an atmospheric resolution of T106 (about $1^{\circ}$ ), the model has considerably more power at frequencies near 3.5 and $5.5 \mathrm{yr}$ (even though the dominant period is still at $2.6 \mathrm{yr}$ ), close to the observed spectra. Such low-frequency behavior has not previously been simulated with coupled GCMs (AchutaRao and Sperber 2002) and is a major new result of this study.

As a measure of El Niño amplitude, the standard deviation of the Niño-3 SST time series is shown in Table 1. Again, by considering the ECHAM4 and HadAM3 families separately, it is apparent that the atmosphere controls the overall level of El Niño activity, although the ocean can modulate it substantially. For example, in the ECHAM4 family, the amplitude of El Niño tends to be weaker than in the HadAM3 family, particularly when the models that share the OPA ocean code are compared. However, within both families, changing the ocean model has a large effect on the activity of El Niño.

From these results, we can identify three prominent features of the modeled El Niño behavior that can be attributed to the atmosphere model: 1) the concentration of power around a dominant mode (regularity); 2) the major role of the atmosphere model in determining the periodicity and amplitude; and 3) the strong impact of a)

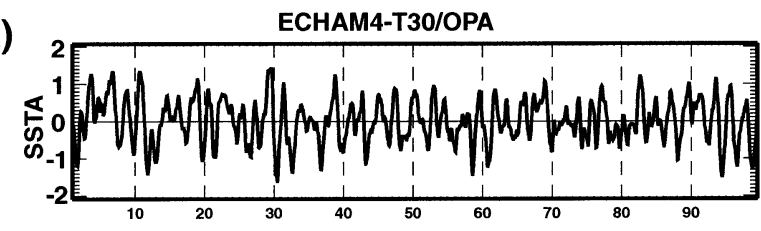

b)

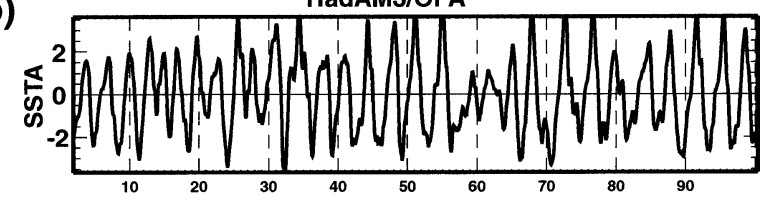

c)

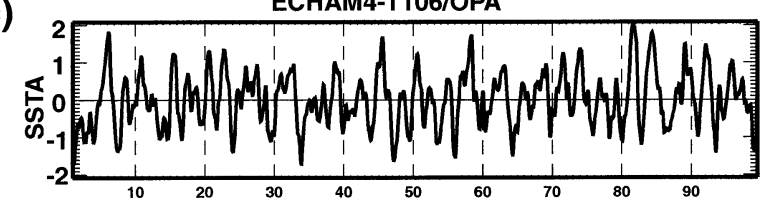

d)

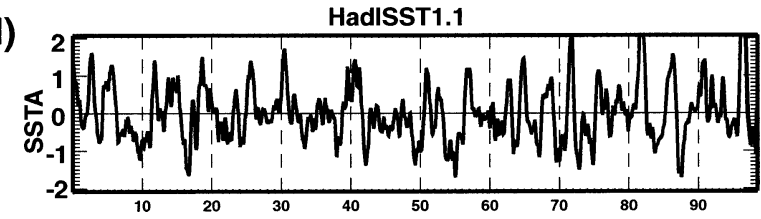

FIG. 4. Niño-3 region SST seasonal anomaly time series (first 100 yr): (a) ECHAM4-T30/OPA, (b) HadAM3/OPA, (c) ECHAM4-T106/ OPA, and (d) HadISST1.1 (years 1900-99). Note the modified vertical scale for HadAM3/OPA.

atmospheric resolution on the regularity and periodicity of El Niño. Although the ocean model appears to modulate the amplitude (but not the periodicity) of El Niño, its role in setting the characteristics of El Niño in the present coupled GCMs appears to be a secondary one.

\section{Discussion}

The results described above demonstrate a dominant role for the atmosphere model in determining El Niño characteristics in coupled GCMs. Whereas most earlier work appeals to delays inherent in ocean wave propagation (Schopf and Suarez 1988; Battisti and Hirst 1989; Jin and Neelin 1993; Kirtman 1997; Jin 1997; Fedorov and Philander 2000), a number of studies point to likely reasons for this result.

First, the coupling strength between the ocean and the atmosphere has been shown to be a key parameter for El Niño frequency in simple coupled models (Zebiak and Cane 1987; Fedorov and Philander 2000). Physically, the coupling strength measures how strongly the atmospheric winds respond to SST anomalies. In the delayed oscillator model, for example, the larger this coupling strength, the longer the El Niño period and the larger its amplitude. In coupled GCMs there is no direct, tunable parameter for the coupling strength, but it can nevertheless vary from one model to another due to variations in the parameterizations of boundary layer, convective processes, or coupling techniques, in partic- 
ular. The atmosphere models used in the present study all have stronger-than-observed trade winds. This reduces their sensitivity to SST changes, ${ }^{2}$ hence the coupling strength, and eventually shortens the periodicity of El Niño (Fedorov and Philander 2000).

The models used in this study have different grids and use different interpolation techniques. This can modify the way in which each component "sees" the other's physics, hence the potential coupling strength. For instance, the equatorial signal in the ocean is strongest in the wave guide, that is, $\left[2^{\circ} \mathrm{S}, 2^{\circ} \mathrm{N}\right]$, and is blurred by the coupling when interpolated to a $4^{\circ}$ atmosphere grid. To understand if the improvement of the ECHAM4-T106/OPA model comes from a better resolution of the ocean-atmosphere coupling, an additional simulation is made (ECHAM4-T106/OPA-mod). In this simulation, the interpolation to and from the atmosphere model is degraded to a T30 resolution, using the interpolation procedure of the ECHAM4-T30/OPA model. The standard deviation of the Niño-3 SST anomalies of the ECHAM4-T106/OPA-mod becomes closer to that of the ECHAM4-T30/OPA model (Fig. 2b), especially outside the spring period, and the low-frequency behavior is somewhat reduced in ECHAM4-T106/OPAmod when compared to ECHAM4-T106/OPA (Fig. 3b), even though it is still stronger than in the ECHAM4T30/OPA model. These results indeed suggest that part of the improvement seen when the atmosphere resolution is increased comes from a better grasp of the details of the modeled SST structures. But they also demonstrate that the qualitative changes obtained when the atmospheric resolution is increased are due to other atmosphere-only processes.

Second, several studies have suggested that the meridional extent of the atmospheric response to tropical SST anomalies can influence the frequency of El Niño (Schopf and Suarez 1990; Kirtman 1997; Guilyardi et al. 2003), with a broader meridional response of the wind generating forced Rossby waves farther off of the equator. These provide a slower negative feedback to the El Niño turnabout in the west Pacific, lengthening the period between two El Niño events. It is notable that a general problem with coupled models (and of those in this study) is the equatorial confinement of the SST signal associated with El Niño (Davey et al. 2001). This bias is somewhat corrected in the ECHAM4-T106/ OPA model (Gualdi et al. 2003) ${ }^{3}$ and may explain the improved El Niño behavior. More generally, the change of the mean state of the modeled climate may contribute significantly to the present results.

The regularity of the simulated El Niño occurs re-

\footnotetext{
${ }^{2}$ Especially during the boreal spring, when, in the observed system, the trade winds relax and small SST changes can induce large atmospheric responses, associated to the "spring predictability barrier."

${ }^{3}$ A comparison of ECHAM4-T106/OPA and ECHAM4-T106/ OPA-mod further indicates that is partly due to the increased meridional resolution in the coupling-not shown.
}

gardless of the formulation of the ocean model, again suggesting that it is related to the atmosphere. Several studies have suggested a central role of "stochastic forcing," mainly provided by the atmosphere, in the stability of the tropical coupled system (Hasselman 1976). Experiments conducted with hybrid coupled models (ocean GCM and statistical atmosphere) have shown that adding a stochastic component to the wind field significantly broadened the El Niño spectral peak (toward lower frequency), hence increasing its irregularity (Kleeman and Moore 1997; Blanke et al. 1997; Eckert and Latif 1997; ZavalaGaray et al. 2003). Such stochastic forcing includes intraseasonal atmospheric variability, and there is increasing evidence that the Madden-Julian oscillation (MJO) may play a crucial role in the initiation and amplification of El Niño (Lengaigne et al. 2004), as was believed to be the case for the 1997/98 event (McPhaden 1999). A notable feature of many AGCMs is their inability to simulate the MJO (Slingo et al. 1996). Although there is some evidence that the MJO is better simulated in coupled models, basic-state errors in the tropical Pacific prevent its propagation eastward and limit westerly wind activity over the equatorial west Pacific (Inness et al. 2003). Hence, it is likely that the combination of weak intraseasonal activity and basicstate errors may limit the stochastic forcing of El Niño by the atmosphere model and contribute to its regularity. A full assessment of the characteristic of the stochastic forcing of the different AGCMs used here is needed to conclude on this point.

Other studies (Tziperman et al. 1994, 1997) have discussed the irregularity of El Niño in the context of simplified ocean-atmosphere models and argued that it is consistent with a low-order chaotic system interacting with the seasonal cycle. The natural oscillator of the equatorial Pacific coupled ocean-atmosphere system can enter into nonlinear resonance with the seasonal cycle at several periods of the oscillator (mostly 2-5 yr). Although the robustness of these results in fully coupled GCMs remains to be shown, these studies may help to relate the regularity of the simulated El Niño to errors in the seasonal cycle or to a lack of seasonal interactions within the equatorial Pacific coupled oceanatmosphere system-both likely in present-day coarse coupled GCMs.

The apparent secondary role played by the ocean can be understood in terms of ocean equatorial dynamics (mostly through Kelvin and forced Rossby waves) whose time scales are fairly predictable. Once these waves are adequately resolved, as is the case for the models used here, an ocean GCM may have little influence on the frequency of El Niño, although the details of the ocean model's physics (e.g., mixing processes) may critically affect the amplitude of El Niño. This argument is supported by the results of this study and others (Cane et al. 1990; Raynaud et al. 2000; Meehl et al. 2001; Schneider 2002; Schneider et al. 2003). However, it is important to stress that the limitations of 
current atmospheric GCMs, which are major contributors to basic-state errors in coupled models, may be a factor in their dominant role; once these limitations are overcome, the importance of the ocean may reemerge, in agreement with present El Niño theories.

\section{Concluding remarks}

This study provides evidence of the dominant role of the atmosphere model in determining El Niño characteristics in present-day state-of-the-art coupled models. Even though this emphasis may be due to shortcomings in present-day atmosphere GCMs, a number of likely mechanisms are put forward to explain it. The major improvements seen when atmospheric resolution is increased agree with studies showing that nonlinear processes (mainly provided by the atmosphere as stochastic motions) are required to transfer El Niño variability power to low frequencies (Munnich et al. 1991; R. Caballero, 2004, personal communication).

This letter also demonstrates the considerable potential of a modular approach to coupled ocean-atmosphere modeling for understanding key drivers of El Niño, and for attributing errors to a specific model component, thus accelerating model development. Although the methodology is used here to elucidate the diversity of El Niño behavior, it can be extended to other modes of variability where coupled processes may matter.

The current study is limited to three model families and clearly a more systematic program of modular coupling experiments would reap additional benefits. This will be facilitated by the multi-institution standardization infrastructure projects underway both in Europe [through the EU FP5 Programme for Integrated Earth System Modelling (PRISM); available online at www.prism.enes.org] and in the United States [Earth System Modeling Framework (ESMF); available online at www.esmf.ucar.edu]. As earth system models combine more and more components, the modular strategy will be a powerful way to understand the intricacies of their complex, nonlinear coupled interactions and guide future model development.

Acknowledgments. The authors acknowledge the work of the teams involved in the development of the GCMs used here. The simulations were carried out in several European supercomputing centres (Met Office, IDRIS, CSAR, MPI/DKRZ, and INGV) and within the EU SINTEX project. We thank the Hadley Centre for providing the HadCM3 (HadAM3/HadOM3) simulation and support for the HadOPA (HadAM3/OPA) project. The constructive comments of two anonymous reviewers are acknowledged. This work was supported by the EU project PRISM (Contract EVR1-CT2001-40012).

\section{REFERENCES}

AchutaRao, K., and K. Sperber, 2002: Simulation of the El Niño Southern Oscillation: Results from the coupled model intercomparison project. Climate Dyn., 19, 191-209.
Battisti, D. S., and A. C. Hirst, 1989: Interannual variability in the tropical atmosphere-ocean system: Influence of the basic state, ocean geometry and nonlinearity. J. Atmos. Sci., 46, 1678-1712.

Blanke, B., J. D. Neelin, and D. Gutzler, 1997: Estimating the effect of stochastic wind forcing on ENSO irregularity. J. Climate, 10, $1473-1486$.

Cane, M. A., M. Munnich, and S. E. Zebiak, 1990: A study of selfexcited oscillations of the tropical ocean-atmosphere system. Part I: Linear analysis. J. Atmos. Sci., 47, 1562-1577.

Davey, M., and Coauthors, 2001: STOIC: A study of coupled model climatology and variability in tropical ocean regions. Climate Dyn., 18, 403-420.

Delecluse, P., M. Davey, Y. Kitamura, S. Philander, M. Suarez, and L. Bengtsson, 1998: TOGA Review Paper: Coupled general circulation modeling of the tropical Pacific. J. Geophys. Res., 103, 14 357-14 373.

Eckert, C., and M. Latif, 1997: Predictability of a stochastically forced hybrid coupled model of El Niño. J. Climate, 10, 1488-1504.

Fedorov, A. V., and S. G. Philander, 2000: Is El Niño changing? Science, 288, 1997-2002.

Gualdi, S., A. Navarra, E. Guilyardi, and P. Delecluse, 2003: Assessment of the tropical Indo-Pacific climate in the SINTEX CGCM. Ann. Geophys., 46, 1-26.

Guilyardi, E., P. Delecluse, S. Gualdi, and A. Navarra, 2003: Mechanisms for ENSO phase change in a coupled GCM. J. Climate, 16, 1141-1158.

Hasselman, K., 1976: Stochastic climate models. Part I: Theory. Tellus, 28, 289-305.

Houghton, J. T., Y. Ding, D. J. Griggs, M. Noguer, P. J. van der Linden, X. Dai, K. Maskell, and C. A. Johnson, Eds., 2001: Climate Change 2001: The Scientific Basis. Cambridge University Press, $881 \mathrm{pp}$.

Inness, P., J. Slingo, E. Guilyardi, and J. Cole, 2003: Simulation of the Madden-Julian oscillation in a coupled general circulation model. Part II: The role of the basic state. J. Climate, 16, 365382.

Jin, F.-F., 1997: An equatorial ocean recharge paradigm for ENSO. Part II: A stripped-down coupled model. J. Atmos. Sci., 54, 830847.

—_ and J. D. Neelin, 1993: Modes of interannual tropical oceanatmosphere interaction-A unified view. Part I: Numerical results. J. Atmos. Sci., 50, 3477-3503.

Kirtman, B. P., 1997: Oceanic Rossby wave dynamics and the ENSO period in a coupled model. J. Climate, 10, 1690-1704.

Kleeman, R., and A. M. Moore, 1997: A theory for the limitation of ENSO predictability due to stochastic atmosphere transients. $J$. Atmos. Sci., 54, 753-767.

Latif, M., and Coauthors, 2001: ENSIP: The El Niño simulation intercomparison project. Climate Dyn., 18, 255-276.

Lengaigne, M., E. Guilyardi, J.-P. Boulanger, C. Menkes, P. Inness, P. Delecluse, and J. Slingo, 2004: Triggering of El Nĩno by westerly wind events in a coupled general circulation model. Climate Dyn., doi:10.1007/s00382-004-0457-2.

McPhaden, M., 1999: Genesis and evolution of the 1997-1998 El Niño. Science, 283, 950-954.

Mechoso, C. R., and Coauthors, 1995: The seasonal cycle over the tropical Pacific in coupled ocean-atmosphere general circulation models. Mon. Wea. Rev., 123, 2825-2838.

Meehl, G. A., P. R. Gent, J. M. Arblaster, B. L. Otto-Bliesner, E. C. Brady, and A. Craig, 2001: Factors that affect the amplitude of El Niño in global coupled climate models. Climate Dyn., 17, $515-526$.

Munnich, M., M. Cane, and S. Zebiak, 1991: A study of self-excited oscillations of the tropical ocean-atmosphere system. Part II: Nonlinear cases. J. Atmos. Sci., 48, 1238-1248.

Neelin, J. D., and Coauthors, 1992: Tropical air-sea interaction in general circulation models. Climate Dyn., 7, 73-104.

Rayner, N., D. Parker, E. Horton, C. Folland, L. Alexander, D. Rowell, E. C. Kent, and A. Kaplan, 2003: Global analyses of sea surface temperature, sea ice, and night marine air temperature since the 
late nineteenth century. J. Geophys. Res, 108, 4407, doi:10.1029/ 2002JD002670.

Raynaud, S., S. Peich, E. Guilyardi, and G. Madec, 2000: Impacts of the ocean lateral diffusion on the El Niño/Southern Oscillation-like variability of a global coupled general circulation model. Geophys. Res. Lett., 27, 3041-3044.

Schneider, E. K., 2002: Understanding differences between the equatorial Pacific as simulated by two coupled GCMs. J. Climate, $\mathbf{1 5}, 449-469$.

— D. D. DeWitt, A. Rosati, B. P. Kirtman, L. Ji, and J. J. Tribbia, 2003: Retrospective ENSO forecasts: Sensitivity to atmosphere model and ocean resolution. Mon. Wea. Rev., 131, 3038-3060.

Schopf, P. S., and M. J. Suarez, 1988: Vacillations in a coupled oceanatmosphere system. J. Atmos. Sci., 45, 3283-3287.

- and - 1990: Ocean wave dynamics and the time scale of ENSO. J. Phys. Oceanogr., 20, 629-645.
Slingo, J., and Coauthors, 1996: Intraseasonal oscillations in 15 atmospheric GCMs: Results from an AMIP diagnostic subproject. Climate Dyn., 12, 325-357.

Tziperman, E., L. Stone, M. A. Cane, and H. Jarosh, 1994: El Niño chaos: Overlapping of resonances between the seasonal cycle and the Pacific ocean-atmosphere oscillator. Science, 264, 7274.

_, S. E. Zebial, and M. A. Cane, 1997: Mechanisms of seasonalENSO interaction. J. Atmos. Sci., 54, 61-71.

Valcke, S., L. Terray, and A. Piacentini, 2000: The OASIS coupled user guide version 2.4. Tech. Rep. TR/CMGC/00-10, CERFACS, $85 \mathrm{pp}$.

Zavala-Garay, J., A. M. Moore, and L. Perez, 2003: The response of a coupled model of ENSO to observed estimates of stochasting forcing. J. Climate, 16, 2827-2842.

Zebiak, S. E., and M. A. Cane, 1987: A model El Niño-Southern Oscillation. Mon. Wea. Rev., 115, 2262-2278. 